\title{
Bilateral Oculomotor Nerve Palsies Due to Posterior Cerebral Arterial Compression Relieved by Microvascular Decompression
}

- Case Report-

\author{
Hidemitsu Nakagawa, Shin NaKaJIMA, Yoshikazu NaKajIMA, \\ Yoshihiro FURUTA, Okihiro NISHI* and Kayo NISHI* \\ Department of Neurosurgery, The Center for Adult Diseases, Osaka, Osaka; \\ *Nishi Ophthalmological Hospital, Osaka
}

\begin{abstract}
A 59-year-old male developed peripheral oculomotor nerve paresis due to compression by the left posterior cerebral artery (PCA), which was successfully treated by microvascular decompression. Two months later, a similar oculomotor nerve paralysis due to the same mechanism occurred contralaterally and was also treated by microvascular decompression. The previous condition was probably caused by arteriosclerotic changes in the PCA, and the following condition by postsurgical adhesion of the arachnoid membrane. The possibility of vascular compression should be considered when oculomotor nerve palsy rapidly develops, although not proven by angiography.
\end{abstract}

Key words: microvascular decompression, oculomotor nerve palsy, posterior cerebral artery

\section{Introduction}

Oculomotor nerve palsy frequently results from compression by an aneurysm at the junction of the internal carotid and the posterior communicating arteries. ${ }^{2,17,18}$ Here, we report a case of bilateral oculomotor nerve compression by the posterior cerebral artery (PCA), which was relieved by microvascular decompression.

\section{Case Report}

A 59-year-old male was hospitalized with left oculomotor nerve paresis in June, 1988 (Fig. 1A). He had no past history of severe headache or family history of neurological disease. The cerebrospinal fluid, erythrocyte sedimentation rate, and other laboratory findings were normal. The glucose tolerance test did not show a diabetic pattern. A computed tomographic (CT) scan found no abnormalities. A left carotid angiogram demonstrated a

Received November 8, 1989; Accepted July 10, 1990 fetal-type posterior communicating artery and a small aneurysm, $0.3 \mathrm{~cm}$ in diameter, at the internal carotid artery proximal to the junction with the posterior communicating artery (Fig. 2 left). A right carotid angiogram found no aneurysm but marked arteriosclerotic changes (Fig. 2 right). Left vertebral angiograms showed the $\mathrm{P}_{2}$ portion of the PCA to form a curve with an anterior convexity, possibly due to arteriosclerosis (Fig. 3).

On July 8, 1988, left frontotemporal craniotomy was performed to prevent aneurysmal bleeding and investigate possible vascular compression of the oculomotor nerve. The aneurysm was too small to cause compression of the oculomotor nerve, being a $3.0 \mathrm{~mm}$ junctional dilatation. From the top of the dilatation, another posterior communicating artery, not demonstrated on the angiograms, extended to the $\mathrm{P}_{2}$ portion of the PCA forming the curve on the angiograms. Thus, the posterior communicating arteries were duplicated, and the curved $\mathrm{P}_{2}$ portion of the PCA severely compressed the oculomotor nerve (Fig. 4A). The nerve was depressed and discolored at the compression site and edematous and swollen at the periphery. The arachnoid membrane 

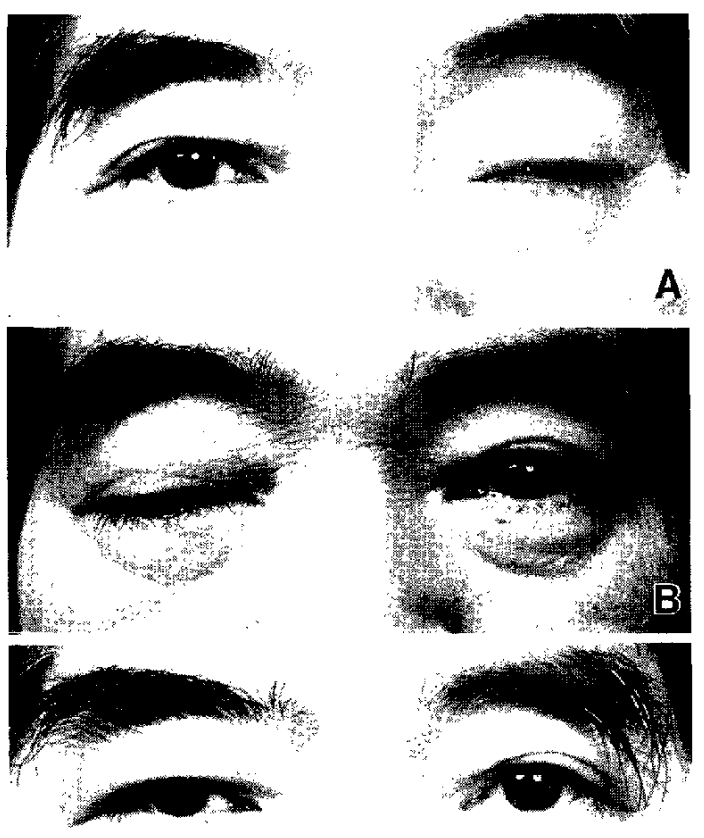

C

Fig. 1 A: Left oculomotor nerve paresis at first admission. B: Right oculomotor nerve paralysis at second admission. $C$ : Recovery from the right oculomotor nerve paralysis 3 months after second operation.

was not hypertrophic. After adequate dissection of the arachnoid membrane around the oculomotor nerve and PCA, the nerve was decompressed by inserting a sponge. The neck of the junctional dilatation was then clipped because it had aneurysmal character.

The impaired ocular movements completely resolved 1 month after the operation, and ptosis subsided 2 weeks later. He was discharged with slight double vision.

Two months after the operation, he suddenly experienced diplopia unaccompanied by headache and, 2 days later, right ptosis. Neurological examination on the second admission showed complete right ptosis (Fig. 1B) with complete absence of adduction, elevation, and depression of the right eye and anisocoria ( $4 \mathrm{~mm}$ right, $3 \mathrm{~mm}$ left). The cerebrospinal fluid was normal. We assumed the oculomotor nerve paralysis to be caused by vascular compression, so a second operation was performed.

A right subtemporal craniotomy discovered elevation of the oculomotor nerve by a tense arachnoid membrane at the tentorial edge. The nerve was severely compressed by the PCA ( $\mathrm{P}_{2}$ portion) at the proximal portion and abnormally hyperemic and swollen at the periphery. The superior cerebellar artery was not attached to the oculomotor nerve (Fig. 4B). The nerve was separated from the arachnoid membrane and decompressed by inserting a sponge between the PCA and the nerve.

One and a half months after the operation, both the impaired ocular movement and ptosis well improved. Within 2 months, the impaired adduction had completely recovered and, 1 month later, elevation of the right eye was only slightly limited together
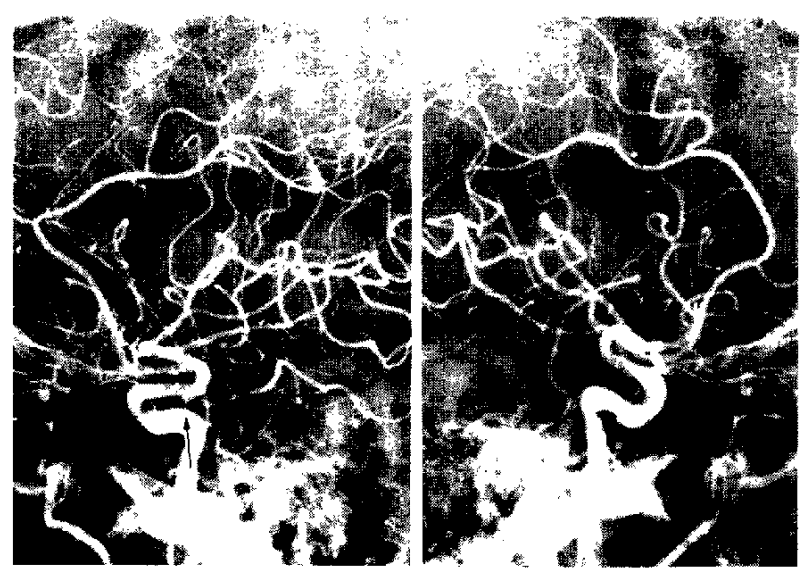

Fig. 2 left: Left carotid angiogram, lateral view, demonstrating an aneurysm (arrow) of the internal carotid artery proximal to the origin of the posterior communicating artery. right: Right carotid angiogram, lateral view, showing arteriosclerotic changes such as elongation and irregularities of the arteries.

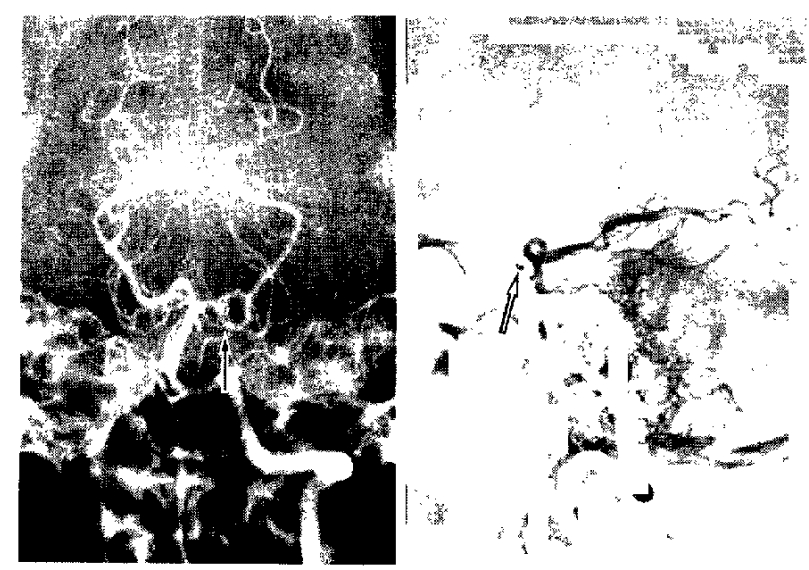

Fig. 3 Left vertebral angiograms, anteroposterior (left) and lateral (right) views, demonstrating marked anterior protrusion (arrow) at the $\mathrm{P}_{2}$ portion of the PCA. 

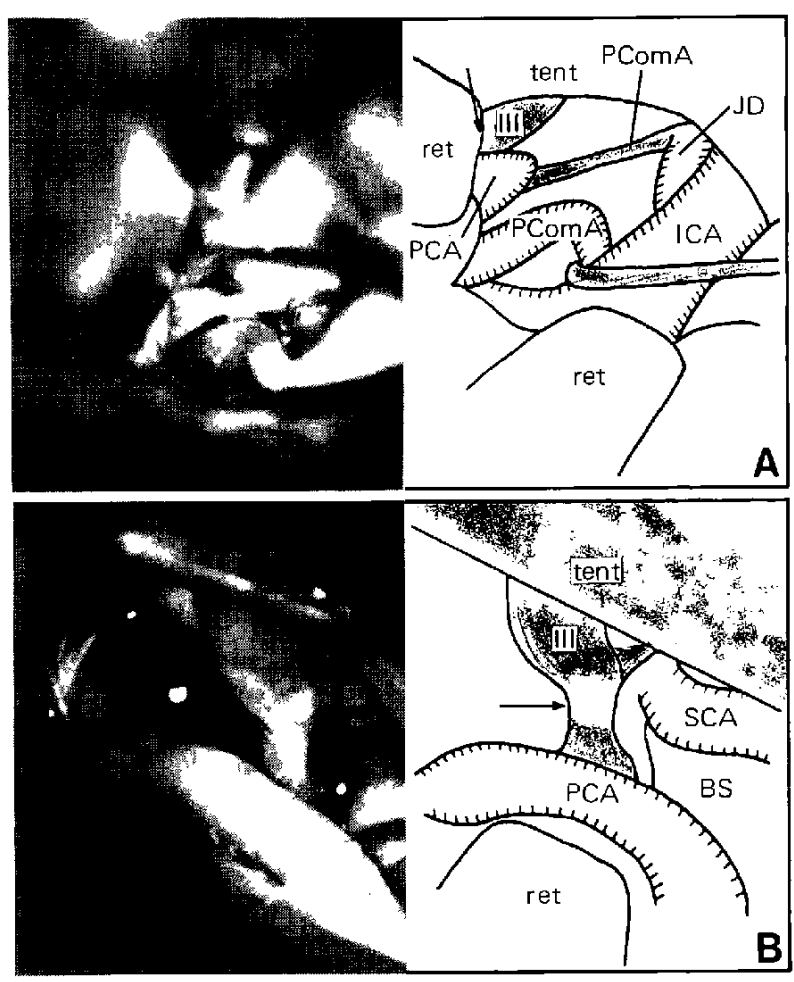

Fig. 4 Microsurgical photographs and diagrams. A: First operation through the left frontotemporal approach. Duplicate posterior communicating arteries (PComA) are shown: small one extending from the top of the junctional dilatation $(\mathrm{JD})$ to the $\mathrm{P}_{2}$ portion of the PCA, and large one distal to the junctional dilatation. The $\mathrm{P}_{2}$ portion of the $\mathrm{PCA}$ compresses the oculomotor nerve (III) forming an anterior convexity (arrow). B: Second operation through the right subtemporal approach. After separating the tense arachnoid membrane and mobilizing the $\mathrm{P}_{2}$ portion of the PCA, the compressed part (arrow) and swollen peripheral portion of the oculomotor nerve are exposed. BS: brainstem, ICA: internal carotid artery, ret: brain retractor, tent: tentorium, SCA: superior cerebellar artery.

with slight ptosis (Fig. 1C). These residual signs completely disappeared, and he became asymptomatic after 1 year. The anisocoria slightly improved but remained detectable even after 1 year.

\section{Discussion}

Vascular compression of the root entry/exit zones or central segments (glial part) of the cranial nerves can cause facial spasm, trigeminal neuralgia, glossopharyngeal neuralgia, ${ }^{91}$ hypertension, ${ }^{(0)}$ vertigo, ${ }^{11,12)}$ and spasmodic torticollis." These conditions are all hyperactive dysfunctions.

Hyperactivity of the oculomotor nerve causing ocular muscle spasm is possibly caused by compression of the central nerve segment. ${ }^{167}$ However, impaired visual acuity and visual fields caused by vascular compression of the optic nerve ${ }^{7,14)}$ are considered to be due to neuropathy. The oculomotor nerve palsy in the present case was likewise a clinical manifestation of neuropathy caused by vascular compression. Generally, hyperactive dysfunction occurs when the central nerve segment with a central myelin sheath, rather than the junctional area between the central and peripheral myelin, suffers vascular compression. In contrast, neuropathy occurs when the cisternal nerve segment without a central myelin is compressed by a vessel. All these conditions can be treated by microvascular decompression.

In addition to aneurysms and vascular anomalies, ${ }^{81}$ the posterior communicating artery may compress the oculomotor nerve. ${ }^{13)} \mathrm{PCA}\left(\mathrm{P}_{1}\right.$ portion) compression of the oculomotor nerve was demonstrated by postmortem examination in a case of suspected ophthalmoplegic migraine $(\mathrm{OM})^{151}$ and in a case of megadolichobasilar anomaly. ${ }^{11}$ These reports also indicated that microvascular decompression relieved oculomotor nerve palsy caused by vascular compression.

Spontaneous recovery from oculomotor nerve palsy is sometimes seen in cases of $\mathrm{OM}^{4.191}$ or diabetes mellitus. ${ }^{3,6)}$ However, the present patient had no history of headache suggesting migraine and laboratory examinations found no sign of diabetes mellitus. At operation, bilateral oculomotor nerves were found to be markedly compressed, with distinct depressions due to vascular compression and peripheral abnormalities. These findings suggest that spontaneous recovery was unlikely.

Our patient first presented with oculomotor nerve paresis due to compression by the PCA, which was treated by microvascular decompression. Two months later, a similar oculomotor nerve paralysis diagnosed as due to the same mechanism occurred contralaterally and was also treated by microvascular decompression. The previous condition was probably caused by arteriosclerotic changes in the PCA, and the following condition by postsurgical adhesions of the arachnoid membrane, although not proven by the operative findings. The possibility of vascular compression should be considered when palsy of all muscles controlled by the oculomotor nerve develops rapidly, even if angiography demonstrates no abnormalities, provided that no other causes can be identified. 


\section{References}

1) Boeri R, Passerini A: The megadolichobasilar anomaly. J Neurol Sci 1: 475-484, 1964

2) Botterell EH, Lloyd LA, Hoffman $\mathrm{HJ}$; Oculomotor palsy due to supraclinoid internal carotid artery berry aneurysm. A long-term study of the results of surgical treatments on the recovery of third-nerve function. Amer J Ophthal 54: 609-616, 1962

3) Dreyfus PM, Hakim S, Adams RD: Diabetic ophthalmoplegia. Report of case, with postmortem study and comments on vascular supply of human oculomotor nerve. Arch Neurol Psychiat 77: 337349, 1957

4) Ehlers H: On the pathogenesis of ophthalmoplegic migraine. Acta Psychiat Scand 3: 219-225, 1928

5) Freckmann N, Hagenah R, Herrmann HD, Müller D: Treatment of neurogenic torticollis by microvascular lysis of the accessory nerve roots: Indication, technique, and first results. Acta Neurochir (Wien) 59: $167-175,1981$

6) Goldstein JE, Cogan DG: Diabetic ophthalmoplegia with special reference to the pupil. Arch Ophthat (Chicago) 64: 592-600, 1960

7) Hilton GF, Hoyt WF: An arteriosclerotic chiasmal syndrome: Bitemporal hemianopia associated with fusiform dilatation of the anterior cerebral arteries. JAMA 196: 1018-1020, 1966

8) Imes RK, Monteiro MLR, Hoyt WF: Ophthalmoplegic migraine with proximal posterior cerebral artery vascular anomaly. J Clin Neuro Ophthalmol 4: 221-223, 1984

9) Jannetta PJ: Observations on the aetiology of trigeminal neuralgia, hemifacial spasm, acoustic nerve dysfunction and glossopharyngeal neuralgia: Definitive microsurgical treatment and results in 117 patients. Neurochirurgia (Stuttg) 20: 145-154, 1977

10) Jannetta PJ: Cranial nerve vascular compression syn- dromes (other than tic douloureux and hemifacial spasm). Clin Neurosurg 28: 445-456, 1981

11) Jannetta PJ: Neurovascular cross-compression of the eighth cranial nerve in patients with vertigo and tinnitus, in Samii M, Jannetta PJ (eds): The Cranial Nerves, Berlin, Springer, 1981, pp 552-555

12) Jannetta PJ, Møller MB, Møller AR: Disabling positional vertigo. $N$ Engl $J$ Med 310: 1700-1705, 1984

13) Kojo N, Lee $S$, Otsuru K, Takagi S, Shigemori $M$, Watanabe $\mathrm{M}$ : A case of ophthalmoplegic migraine with cerebral aneurysm. No Shinkei Geka 16: 503507, 1988 (in Japanese)

14) Matsuo K, Kobayashi S, Sugita K: Bitemporal hemianopsia associated with sclerosis of the intracranial internal carotid arteries. Case report. $J$ Neurosurg 53: $566-569,1980$

15) Morimoto $K$, Nagatani $M$, Mogami $H$ : A case simulating ophthalmoplegic migraine: Clinicopathological study. Headache 25: 426-428, 1985

16) Ricker K, Mertens HG: Okuläre Neuromyotonie. Klin Mbl Augenheilk 156/6: 837-842, 1970

17) Soni SR: Aneurysms of the posterior communicating artery and oculomotor paresis. I Neurol Neurosurg Psychiatry 37: 475-484, 1974

18) Walker AE: Clinical localization of intracranial aneurysms and vascular anomalies. Neurology (Minneap) 6: 79-90, 1956

19) Walsh JP, O'Doherty DS: A possible explanation of the mechanism of ophthalmoplegic migraine. Neurology (Minneap) 10: 1079-1084, 1960

Address reprint requests to: H. Nakagawa, M.D., Department of Neurosurgery, The Center for Adult Diseases, Osaka, 1-3-3 Nakamichi, Higashinari-ku, Osaka 537, Japan. 